\title{
Skin Capillary Blood Flow in Scleroderma
}

\author{
E. Carwile LeRoy, John A. Downey, and Paul J. Cannon \\ From the Departments of Medicine and Rehabilitation Medicine, Columbia \\ University College of Physicians and Surgeons, and the Edward Daniels \\ Faulkner Arthritis Clinic of the Presbyterian Hospital, New York 10032
}

\begin{abstract}
A B S T R A C T Skin blood flow was measured by the clearance of radioactive xenon $\left({ }^{13} \mathrm{Xe}\right)$ injected intracutaneously in eight patients with scleroderma and nine control subjects under conditions of controlled temperature and humidity. Scleroderma patients, on being cooled $1 \mathrm{hr}$ at $18^{\circ} \mathrm{C}$, had a rate constant of ${ }^{133} \mathrm{Xe}$ clearance from the dorsal finger skin which was $0.04 \pm 0.07 \mathrm{~min}^{-1}$ (mean $\pm \mathrm{SD}$ ), compared with $0.23 \pm 0.15 \mathrm{~min}^{-1}$ in normal subjects $(P<0.005)$. The corresponding mean cutaneous blood flows were $2.9 \mathrm{ml} / 100 \mathrm{~g}$ per $\mathrm{min}$ in the scleroderma patients and $16.4 \mathrm{ml} / 100 \mathrm{~g}$ per min in normal subjects. After reflex warming by waterbath, clearance was similar in the two groups $(0.33 \pm 0.1$ vs. 0.40 $\pm 0.09)$; these data suggest that diminished clearance in scleroderma patients on cooling resulted, at least in part, from functional or reversible interruption of the circulation. The skin temperatures of scleroderma patients after reflex warming remained lower than those of normal subjects, despite similar increases in sublingual temperatures. The dissociation of ${ }^{183} \mathrm{Xe}$ clearance and skin temperature in scleroderma patients (i.e. subnormal skin temperatures with normal ${ }^{183} \mathrm{Xe}$ clearance after reflex warming) suggests either abnormal thermal properties of scleroderma skin or selective vasoconstriction of the vessels which regulate heat exchange. The demonstrated interruption of the capillary circulation on cooling of the skin in patients with scleroderma may be important in the pathogenesis of this disorder. After oral pretreatment with guanethidine, five patients with scleroderma had increased ${ }^{133} \mathrm{Xe}$ clearance and calculated blood flow on cooling, rising to normal in three of these patients. The potential of this technique for the quantitative sequential evaluation of skin blood flow in subjects with scleroderma and for the evaluation of empirical therapy is suggested.
\end{abstract}

\section{INTRODUCTION}

The striking fibrosis and atrophy of skin in scleroderma (systemic sclerosis) have prompted several investigators

Received for publication 8 May 1970 and in revised form 2 December 1970. to search for structural abnormalities of dermal connective tissue $(1,2)$. In contrast, the presence of a vascular defect has received less emphasis, and abnormalities of the circulation have been studied largely by indirect means and in the later stages of the disease (3). The clinical features early in scleroderma which implicate the circulation in its pathogenesis include: Raynaud's phenomenon which usually precedes skin changes, cutaneous edema early in scleroderma, telangiectasia, and nailfold and ultrastructural capillary abnormalities of skin and muscle (4-7). Widespread vascular abnormalities observed in many viscera at postmortem examination also suggest a vascular component in this disorder $(8,9)$. Despite these morphological suggestions of a widespread abnormality in capillary structure in scleroderma, no quantitative assessment of capillary function, i.e. nutrient blood flow, has been reported previously.

In an attempt to define scleroderma at a stage before the irreversible "hidebound" fibrosis, skin blood flow at the capillary level was measured from the local clearance rate of ${ }^{133} \mathrm{Xe}$ in normal and scleroderma subjects in a temperature-controlled environment. Measurements of skin and sublingual temperature, as well as separate ${ }^{133} \mathrm{Xe}$ clearance determinations, were performed during cooling and after reflex warming in the two groups. The data provide evidence that $(a)$ during a period of cooling, skin blood flow is distinctly reduced in scleroderma patients when compared with normal subjects, (b) blood flow in scleroderma skin during reflex warming (finger) and at room temperature $\left(24^{\circ} \mathrm{C}\right.$, forearm) is similar to that of normal skin, and (c) during reflex warming of scleroderma patients, skin temperatures are subnormal despite normal cutaneous blood flow, suggesting either an abnormal thermal conductivity of the skin in this disorder, or a dissociation in flow between shunting vessels and the capillary circulation.

\section{METHODS}

Skin blood flow was measured by the clearance of ${ }^{193 \mathrm{Xe}}$ according to the technique of Sejrsen (10-12). This is a modification of Kety's method for determining blood flow 
per gram tissue from the local clearance of a radioactive inert gas $\left({ }^{133} \mathrm{Xe}\right)$ injected directly into the tissue. The technique is based upon the following assumptions: $(a)$ constant blood and lymph flow during the measurement, (b) rapid and continuous diffusion equilibrium between the tissue perfused and capillary blood, $(c)$ the presence of one or more zones each with homogeneous perfusion, $(d)$ no loss of inert gas by routes other than venous blood, and $(e)$ the absence of recirculation of indicator. After intracutaneous injection of ${ }^{133} \mathrm{Xe}$, the decline of radioactivity at the injection site is monitored externally and the washout curve so obtained is analyzed graphically in terms of a two-compartment model proposed by Sejrsen (12). By this approach, cutaneous blood flow is calculated from the rate constant of the faster component (component I) of the conventional biexponential resolution of the isotope washout curve and from the tissue: blood partition coefficient $(\lambda)$ for ${ }^{133} \mathrm{Xe}(10)$. The slower component (component II) has been shown to depend largely on isotope accumulation in subcutaneous fat, and has been subtracted from all biexponential washout curves (10).

Nine multidetermination studies were carried out in eight female subjects with varying degrees of definite scleroderma (see Table I). Patients with clinical features of rheumatoid arthritis, systemic lupus erythematosus, or dermatomyositis were excluded. Nine presumably healthy female subjects, with normal skin and no history of unusual cold sensitivity, served as age-matched controls. Subjects were studied 4-12 $\mathrm{hr}$ after eating and more than $24 \mathrm{hr}$ after taking tobacco, ethanol, caffaine, or any medications. Informed consent was obtained before study; radiation exposure was less than 1.0 mrad.

All studies were performed in a temperature- and humidity-controlled room with a relative humidity of $50 \%$; the temperature varied with the protocol used. Temperatures were measured with copper-constantan thermocouples sublingually (mouth taped shut) and on the skin at eight sites: the pad of the second finger tip (left and right), the dorsum of the proximal phalanx of the second and fourth fingers (left and right), and the volar forearm $11 \mathrm{~cm}$ proximal to the palmar-forearm skin crease (left and right). Wall (of the room), ambient, and water bath temperatures were monitored from multiple sites. All temperatures were recorded at $0.8-\mathrm{min}$ intervals on a Honeywell multipoint recorder (Honeywell Inc., Test Instruments Div., Denver, Colo. 80217 ) with an accuracy of $0.05^{\circ} \mathrm{C}$. To quantify heat input during reflex warming, oral temperatures were plotted against time, and a line drawn through the temperatures obtained during cooling was extended through the period of reflex warming. The area between this base line and a line produced by rising oral temperatures during warming was measured with a hand planimeter from the onset of warming to the completion of ${ }^{133} \mathrm{Xe}$ clearance.

${ }^{123} \mathrm{Xe}$ clearance was determined by injecting intracutaneously into the dorsal skin of the proximal phalanx of the third finger $80-100 \mu \mathrm{Ci}{ }^{135} \mathrm{Xe}$ (Neisler Laboratories, Tuxedo, N. Y.), dissolved in $0.01-0.03 \mathrm{ml}$ sterile isotonic saline, with No. 30 needles and 50-100 $\mu 1$ "gastight" syringes (Hamilton Manufacturing Co., Wash., D. C.). Left and right hands were alternately chosen. The decline in radioactivity was monitored for 20-30 min with a 2 inch sodium iodide scintillation crystal, positioned $12-15 \mathrm{~cm}$ above the injection site, and arranged perpendicular to the skin within a cylindrical lead collimator. Counts were accumulated for $5 \mathrm{sec}$ intervals; the counts of each interval were converted to net counts per min and plotted semilogarithmically against time as the percentage of peak counts per minute. The curves were characterized by graphic analysis (13) from which half- times $\left(t_{\frac{1}{2}}\right)$ were measured and clearance constants $(K)$ were calculated as outlined below. After plotting the data from each interval, a line was drawn tangent to the points between 15 and $20 \mathrm{~min}$ and extrapolated to zero time. This line is component II; the radioactivity represented by this line at each time point was subtracted from the original curve and a new curve was constructed. A straight line drawn through the points of the subtracted curve is component I. Clearance or rate constant $(K)$ was determined from the slope of component I (or component II when curves were monoexponential) by the expression, $K=$ $0.693 / \mathrm{t}_{\frac{1}{2}}$ in $\mathrm{min}$.

Cutaneous blood flow was calculated from the equation:

$$
\mathrm{F}, \mathrm{ml} / 100 \mathrm{~g} \text { per } \min =\frac{K \cdot \lambda \cdot 100}{\rho}
$$

where,

$$
\begin{aligned}
K & =\text { clearance constant, } \frac{\ln 2}{t_{3}}=0.693 / \mathrm{t}_{3} \\
\lambda & =\begin{array}{c}
\text { tissue }: \text { blood partition coefficient, } 0.7 \mathrm{ml} / \mathrm{g} \text { for }{ }^{133 \mathrm{Xe}} \\
\text { in normal skin (10) }
\end{array} \\
\rho & =\text { specific gravity of tissue, } 1.0 \text { for normal skin }
\end{aligned}
$$

For flow calculations to be valid in comparing scleroderma patients and normal subjects, two assumptions, in addition to the basic assumptions of the method mentioned above, are necessary, i.e., that $\lambda$ and $\rho$ for scleroderma skin are similar to normal. Although indirect evidence is consistent with these assumptions (see Discussion), no direct measurements are available; therefore, flow data are presented separately from clearance data, as the latter are not affected by assumptions involving $\lambda$ and $\rho$. The value of $\lambda$ for ${ }^{133} \mathrm{Xe}$ (a lipophilic gas), is influenced by ${ }^{133} \mathrm{Xe}$ binding to both hemoglobin and albumin $(14,15)$. Differences of $\lambda$ attributable to the hemoglobin and albumin concentrations in the patients studied would be small ( $5 \%$ or less); the data have not been corrected for these variables.

On the day of study the subject entered the constant temperature room $\left(17.5-18.0^{\circ} \mathrm{C}\right)$ and sat comfortably and quietly in an adjustable dental chair. All subjects were lightly clothed, with arms and legs bare and shoes removed. Thermocouples were placed and, after $60-70 \mathrm{~min}$ of equilibration, ${ }^{133} \mathrm{Xe}$ was injected as described. The intracutaneous deposition of isotope was confirmed in all subjects by hair follicle indentation (peau d'orange effect); if isotope was injected subcutaneously, the study was not used. Bubbles in the syringe were eliminated by preloading the syringe and needle dead space with saline. After the period of monitoring ${ }^{133} \mathrm{Xe}$ disappearance $(20-30 \mathrm{~min})$, the hand and arm just tested were placed in a circulating water bath $\left(44^{\circ} \mathrm{C}\right)$ previously shielded from the subject. The legs were covered to speed warming of the untested hand. When no further increase in oral temperature had occurred for 8-12 $\mathrm{min}$, a second ${ }^{133} \mathrm{Xe}$ injection was carried out at the comparable site on the untested hand. The arm remained in the water bath while the second ${ }^{133} \mathrm{Xe}$ injection was monitored (20-30 min).

A second protocol was used to study forearm skin blood flow at comfortable room temperature in six normal and six scleroderma subjects. The lightly clothed subject entered a $24^{\circ} \mathrm{C}$ room and sat for an hour during which thermocouples were placed: ${ }^{133} \mathrm{Xe}$ was injected intracutaneously in the volar skin of the forearm $11 \mathrm{~cm}$ above the palmarforearm skin crease. Isotope disappearance was monitored for $60 \mathrm{~min}$ as previously described. All data were compared 
TABLE I

Clinical and Blood Flow Data

\begin{tabular}{|c|c|c|c|c|c|c|c|c|c|}
\hline \multirow[b]{2}{*}{ Subject } & \multirow[b]{2}{*}{ Age } & \multirow[b]{2}{*}{$\begin{array}{c}\text { System } \\
\text { involvement }\end{array}$} & \multirow[b]{2}{*}{ Duration } & \multirow[b]{2}{*}{$\begin{array}{c}\text { Skin involve- } \\
\text { ment at } \\
\text { injection site, } \\
\text { severity }\end{array}$} & \multirow[b]{2}{*}{$\begin{array}{l}\text { Prior } \\
\text { therapy }\end{array}$} & \multicolumn{2}{|c|}{$\begin{array}{c}\text { In cool room } \\
\left(18^{\circ} \mathrm{C}\right)\end{array}$} & \multicolumn{2}{|c|}{$\begin{array}{l}\text { During reflex } \\
\text { warming }\end{array}$} \\
\hline & & & & & & $\begin{array}{l}\text { Clearance } \\
\text { constant } \\
(K)\end{array}$ & $\begin{array}{l}\text { Blood } \\
\text { flow } \\
(F)\end{array}$ & $\begin{array}{l}\text { Clearance } \\
\text { constant } \\
(K)\end{array}$ & $\begin{array}{l}\text { Blood } \\
\text { flow } \\
(F)\end{array}$ \\
\hline & $y r$ & & $y r$ & & & & $\begin{array}{l}m l / 100 \\
g \text { per min }\end{array}$ & & $\begin{array}{l}m l / 100 \\
g \text { per min }\end{array}$ \\
\hline \multicolumn{10}{|c|}{ Scleroderma Subjects } \\
\hline 1. J. E. & 44 & Skin, esophagus & & Moderate & $\begin{array}{l}\text { Hydroxyzine } \\
\text { (Atarax) }\end{array}$ & 0.030 & 2.1 & 0.41 & 28.7 \\
\hline 2. A. McD.* & 39 & $\begin{array}{l}\text { Skin, lungs, } \\
\text { esophagus }\end{array}$ & 8 & Mild & None & 0.237 & 16.6 & 0.40 & 28.0 \\
\hline $\begin{array}{l}\text { 3. N. K. } \\
\text { 4. B. G. }\end{array}$ & $\begin{array}{l}41 \\
47\end{array}$ & $\begin{array}{l}\text { Skin, esophagus } \\
\text { Skin, lungs }\end{array}$ & $\begin{array}{c}9 \\
4 / 12\end{array}$ & $\begin{array}{l}\text { Severe } \\
\text { Mild }\end{array}$ & $\begin{array}{l}\text { Potaba } \\
\text { None }\end{array}$ & $\begin{array}{l}0.023 \\
0.028\end{array}$ & $\begin{array}{l}1.61 \\
1.96\end{array}$ & $\begin{array}{l}0.26 \\
0.34\end{array}$ & $\begin{array}{l}18.2 \\
23.8\end{array}$ \\
\hline 5. J. E. & & \multicolumn{3}{|c|}{ Same as subject 1} & & 0.011 & 0.77 & 0.34 & 23.8 \\
\hline 6. I. L. & 49 & $\begin{array}{l}\text { Skin, breast } \\
\text { carcinoma }\end{array}$ & 5 & Mild & Salicylates & 0.014 & 0.98 & 0.53 & 37.0 \\
\hline 7. E. R. & 40 & $\begin{array}{l}\text { Skin, lungs, } \\
\text { esophagus }\end{array}$ & 7 & Mild & None & 0.010 & 0.70 & 0.26 & 18.2 \\
\hline 8. I. O'C & 33 & Skin & 2 & Severe & Guanethedinef & 0.011 & 0.77 & 0.22 & 15.4 \\
\hline \multirow[t]{2}{*}{ 9. $\mathrm{K} . \mathrm{McN}$. } & 32 & Skin, lungs & 4 & Severe & Guanethedineः & 0.015 & 1.05 & 0.21 & 14.7 \\
\hline & & & & & Mean \pm SD & $\begin{array}{r}0.04 \\
\pm 0.07\end{array}$ & $\begin{aligned} & 2.94 \\
\pm & 5.1\end{aligned}$ & $\begin{array}{r}0.33 \\
\pm 0.10\end{array}$ & $\begin{array}{r}23.1 \\
\pm 7.3\end{array}$ \\
\hline Normal Subjects & & & & & & & & & \\
\hline 1. J. C. & 43 & Healthy & & & None & 0.346 & 24.2 & 0.51 & 35.7 \\
\hline 2. E. F. & 40 & Healthy & & & None & 0.470 & 32.9 & \multicolumn{2}{|c|}{$\begin{array}{c}\text { Subcutaneous } \\
\text { injection }\end{array}$} \\
\hline 3. B. H. & 45 & Healthy & & & None & 0.198 & 13.85 & 0.44 & 30.8 \\
\hline 4. M. F. & 53 & Healthy & & & None & 0.022 & 1.54 & 0.27 & 18.9 \\
\hline 5. N. E. & 38 & Healthy & & & None & 0.187 & 13.1 & 0.39 & 27.3 \\
\hline 6. A. J. & 45 & Healthy & & & None & 0.019 & 1.33 & 0.46 & 32.2 \\
\hline 7. R. D. & 46 & Healthy & & & None & 0.296 & 20.7 & 0.46 & 32.2 \\
\hline 8. M. McC. & 50 & Healthy & & & None & 0.210 & 14.7 & 0.26 & 18.2 \\
\hline \multirow[t]{3}{*}{ 9. E. D. } & 44 & Healthy & & & None & 0.364 & 25.5 & 0.41 & 28.7 \\
\hline & & & & & Mean \pm SD & $\begin{array}{r}0.23 \\
\pm 0.15\end{array}$ & $\begin{array}{r}16.4 \\
\pm 10.6\end{array}$ & $\begin{array}{r}0.40 \\
\pm 0.09\end{array}$ & $\begin{array}{r}28.0 \\
\pm 6.3\end{array}$ \\
\hline & & & & & $P \S$ & $<0.005$ & $<0.005$ & $>0.1$ & $>0.1$ \\
\hline
\end{tabular}

* Studied during period of pulmonary insufficiency with hypoxia, which may have prevented vasoconstriction (Raynaud's phenomenon not observed). ¥ Therapy discontinued 4-6 wk before test.

\& Compares normal and scleroderma groups by Student's $t$ test.

statistically as unpaired variables using Student's $t$ test, except the data in Table III (guanethedine) which were compared as paired variables.

\section{RESULTS}

Methodologic studies. Four preliminary studies were carried out before comparisons of normal and scleroderma subjects. First, the effect of injection volume on the ${ }^{123} \mathrm{Xe}$ washout curve was determined; saline in excess of $0.1 \mathrm{ml}$ delayed isotope washout as previously reported for ${ }^{183} \mathrm{Xe}(10)$ and for radiosodium (16). In the present study injection volumes were usually $0.01-$ $0.04 \mathrm{ml}$ and did not exceed $0.07 \mathrm{ml}$ (Table II). Second, monitoring periods of $20 \mathrm{~min}$ and $2 \mathrm{hr}$ were compared. The $t_{3}$ of component II was similar to half-times reported by others $\left(t_{1}=150-300 \mathrm{~min}\right)(10)$ and no consistent differences were observed between 20 -min and 2 -hr periods of monitoring isotope washout. Subsequent studies were monitored for 20-30 min. Third, the effect of arterial occlusion (cuff inflated to $160 \mathrm{~mm} \mathrm{Hg}$ ) on ${ }^{13} \mathrm{Xe}$ washout was studied in two normal subjects. No decline of radioactivity was observed in either subject over a 20 -min period. Fourth, ${ }^{188} \mathrm{Xe}$ clearance was compared in the right and left forearms of four normal subjects. No significant differences in the cutaneous clearances of the two sides were noted.

An analysis of the conditions prevailing during the comparison of skin blood flow in normal and scleroderma subjects is shown in Table II. Injection volume, equilibration time during cooling, wall and ambient temperatures, sublingual temperatures, and skin temperatures at the site of injection during cooling did not differ significantly between the two grouns. Selocted clinical features which characterize the two groups are shown in Table I.

Cutaneous blood flow at $18^{\circ} \mathrm{C}$. After equilibration at $18^{\circ} \mathrm{C}$ for $1 \mathrm{hr}$, oral and dorsal finger skin temperatures were comparable in normal and scleroderma subjects 
TABLE II

Comparison of Test Conditions

\begin{tabular}{|c|c|c|c|c|c|c|c|c|}
\hline & \multicolumn{4}{|c|}{ During cooling } & \multicolumn{4}{|c|}{ During warming } \\
\hline & \multicolumn{2}{|c|}{ Normal (9) } & \multicolumn{2}{|c|}{ Scleroderma (9) } & \multicolumn{2}{|c|}{ Normal (9) } & \multicolumn{2}{|c|}{ Scleroderma (9) } \\
\hline & Mean & SE & Mean & SE & Mean & SE & Mean & SE \\
\hline Injection volume, $m l$ & 0.034 & \pm 0.008 & 0.037 & \pm 0.006 & 0.035 & \pm 0.008 & 0.037 & \pm 0.006 \\
\hline Equilibration, ${ }^{*} \min$ & 67.3 & \pm 3.3 & 62.4 & \pm 5.1 & 34.9 & \pm 4.0 & 46.0 & \pm 2.4 \\
\hline \multicolumn{9}{|l|}{ Temperatures, ${ }^{\circ} \mathrm{C}$} \\
\hline Wall & 18.5 & \pm 0.2 & 18.2 & \pm 0.1 & 18.4 & \pm 0.3 & 18.1 & \pm 0.1 \\
\hline Ambient & 19.0 & \pm 0.1 & 18.0 & \pm 0.2 & 17.8 & \pm 0.1 & 18.2 & \pm 0.1 \\
\hline $\begin{array}{l}\text { Skin, site of injection } \\
\text { Sublingual }\end{array}$ & 21.8 & \pm 0.6 & 21.6 & \pm 0.3 & 33.8 & \pm 0.5 & 25.9 & \pm 0.9 \\
\hline Low & 36.8 & \pm 0.2 & 36.7 & \pm 0.3 & & - & & - \\
\hline High & & - & & - & 37.8 & \pm 0.9 & 37.9 & \pm 0.1 \\
\hline Difference & & & & & 1.07 & \pm 0.1 & 1.26 & \pm 0.3 \\
\hline
\end{tabular}

* Time in cool room during cooling; time of arm in water bath up to second ${ }^{133} \mathrm{Xe}$ injection during warming.

(Table II). All scleroderma subjects except one (Table I, A. McD.), were observed to have numbness, cyanosis, or pallor of the fingers (the initial phase of Raynaud's phenomenon) while in the $18^{\circ} \mathrm{C}$ room. A characteristic ${ }^{138} \mathrm{Xe}$ washout curve from the digital skin of a normal subject is shown in Fig. 1 (normal). This curve was easily resolved into two components, as were all curves from normal subjects. The clearance values for component I, obtained by subtracting component II from the original curve, are shown in Table I, as are cutaneous blood flows calculated from the rate constant of component I.

A washout curve from the dorsal finger skin of a patient with scleroderma is shown in Fig. 1 (scleroderma). In this patient and in seven other studies of patients with scleroderma, a rapid component of the washout curve could not be obtained by graphic analysis; attempted subtraction of component II yielded a random scatter of points to which no line could be fitted. In these patients, half-times, clearance constants, and calculated flow data are derived from the monoexponential curves. A comparison of ${ }^{128} \mathrm{Xe}$ washout curves obtained at $18^{\circ} \mathrm{C}$ in four normal and five scleroderma subjects is shown in Fig. 2. The clearance and calculated flow data for all subjects are shown in Table I. There was a statistically significant difference $(P<$ 0.005 ) between the clearance constants (and calculated cutaneous blood flows) of normal subjects and scleroderma patients at this temperature. Skin temperatures were similar in the two groups despite the observed differences in ${ }^{203} \mathrm{Xe}$ clearance. No basis for the low ${ }^{133} \mathrm{Xe}$ clearances of two control subjects (M. F. and A. J.) was revealed by history or physical examination. There was a correlation between lower clearance and increasing age in the normal and scleroderma groups after reflex warming; it is possible that the ages of subjects M. F. and A. J. were factors in the observed low clearance during cooling. The absence of Raynaud's phenomenon and the rapid ${ }^{13} \mathrm{Xe}$ clearance in one scleroderma subject (A. McD.) could have been caused by coexistent respiratory insufficiency and hypoxia at rest.

Temperature response. The response of skin and body temperatures in a representative normal and scleroderma subject after cooling and subsequent warming is shown in Figs. 3 and 4, respectively. Mean temperature data for all subjects are shown in Table II. The

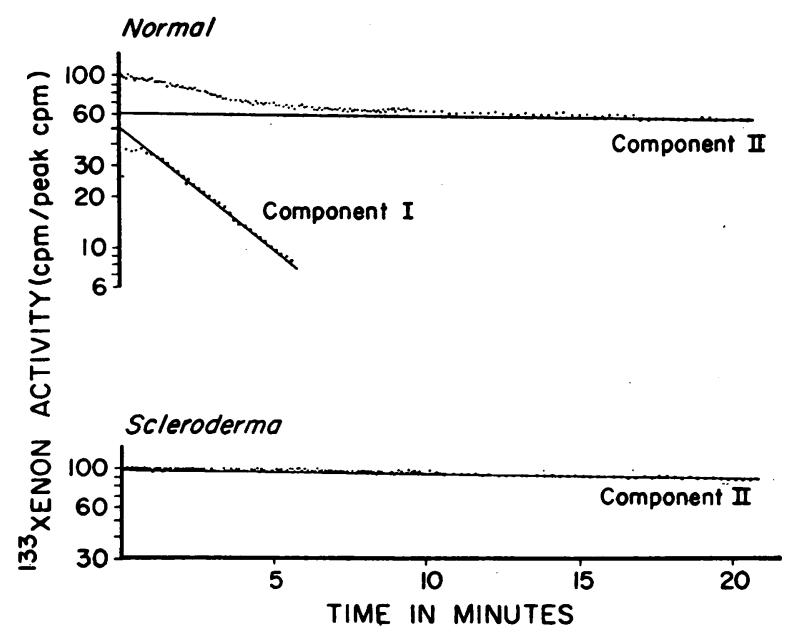

Figure 1 Normal: complete curve of ${ }^{183} \mathrm{Xe}$ washout in a normal subject after cooling. Component I was obtained by graphic analysis as described in the text (see Methods). Scleroderma: complete curve of ${ }^{183} \mathrm{Xe}$ washout in a subject with scleroderma after cooling. Attempted graphic analysis resulted in an unresolvable set of points.

Skin Capillary Blood Flow in Scleroderma 
NORMAL

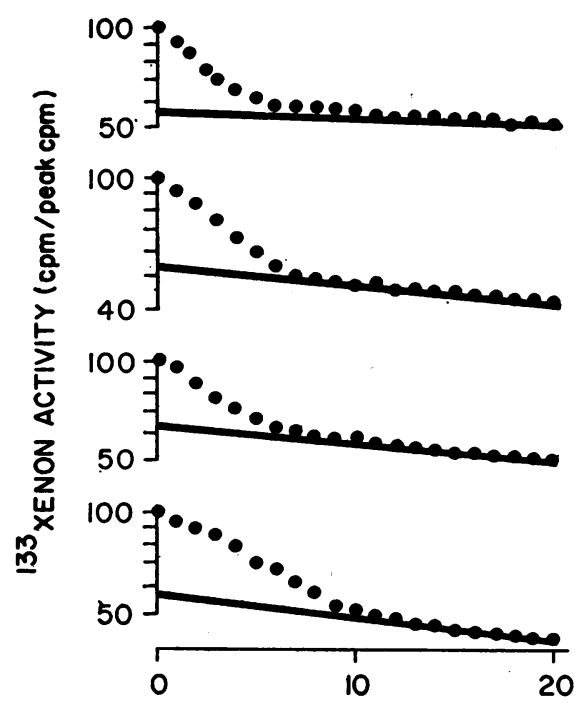

SCLERODERMA
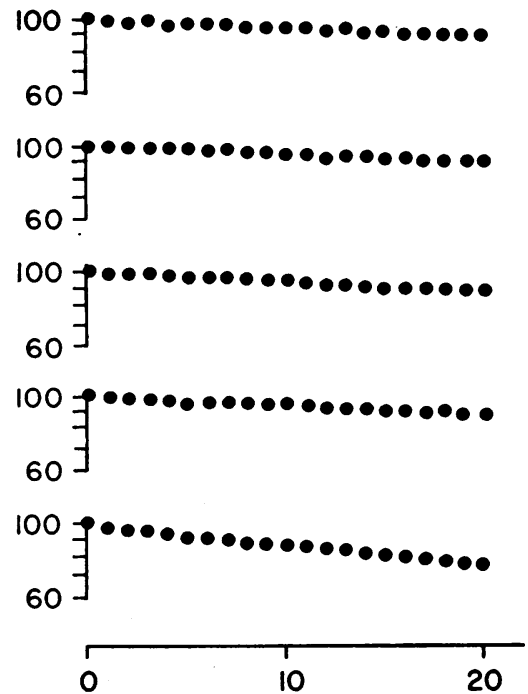

TIME IN MINUTES

FIGURE 2 Disappearance curves of ${ }^{188} \mathrm{Xe}$ during cooling in four normal subjects and five scleroderma subjects. The rapid clearance seen early in the normal subjects was absent in eight of the nine scleroderma studies. Every eleventh point is shown.

degree and rate of cooling were similar in the two groups. In normal subjects, the response of finger skin to reflex warming began within minutes, proceeded rapidly, and reached a definite plateau with little further increase. In scleroderma subjects, the skin temperature response to warming was delayed, the rate of response was slower, and a definite plateau was often not achieved. Due to this slow response to warming in scleroderma patients, their arms were immersed longer in the waterbath (Table II, 46 vs. $34.9 \mathrm{~min}$ ). Despite a longer period of reflex warming, the finger skin temperatures of the patients remained significantly cooler (mean $25.9^{\circ} \mathrm{C}$ ) than those of the control group (mean $33.8^{\circ} \mathrm{C}$ ). This diminished response to warming cannot be explained by inadequate uptake of heat from the water bath: the rise in sublingual temperature $\left(1.25\right.$ vs. $1.07^{\circ} \mathrm{C}$, Table II) and the areas under the sublingual temperature curves measured in arbitrary planimetry units from the onset of warming to the completion of ${ }^{183} \mathrm{Xe}$ clearance were equal or greater in scleroderma subjects (normal, $0.064 \pm 0.01$; scleroderma, $0.092 \pm 0.002$ ). These data indicate that an adequate "afferent" stimulus was achieved.

Cutaneous blood flow after reflex warming. A second ${ }^{123} \mathrm{Xe}$ clearance was determined after reflex warming in all scleroderma and eight of nine normal subjects (Table I). Clearance curves in one normal and one scleroderma subject during cooling and warming are shown in Fig. 5 and are representative of the two groups. All subjects showed an increase in ${ }^{128} \mathrm{Xe}$ clearance, and, in contrast to the monoexponential washout curves observed in the same patients at $18^{\circ} \mathrm{C}$, all curves obtained after warming consisted of two components. The mean ${ }^{128} \mathrm{Xe}$ clearance of normal subjects was 0.40 $\min ^{-1}$ (range $0.26-0.51 ;$ mean $\pm 2 \mathrm{SD}=0.22-0.58$ ). Seven of nine scleroderma subjects showed an increase in clearance to or beyond the normal range $(0.26-0.53)$. The increase in clearance and calculated blood flow

TABLE III

Effect of Guanethedine on ${ }^{133} \mathrm{Xe}$ Clearance during Cooling

\begin{tabular}{|c|c|c|c|c|}
\hline \multirow[b]{2}{*}{ Subject } & \multicolumn{2}{|c|}{$\begin{array}{l}\text { Clearance constant } \\
(K)\end{array}$} & \multicolumn{2}{|c|}{$\begin{array}{l}\text { Blood flow } \\
\quad(F)\end{array}$} \\
\hline & Before & After & Before & After \\
\hline & & & \multicolumn{2}{|c|}{$m l / 100 \mathrm{~g}$ per $\min$} \\
\hline 1 & 0.013 & 0.231 & 0.91 & 16.2 \\
\hline 2 & 0.048 & 0.224 & 3.36 & 15.7 \\
\hline 3 & 0.029 & 0.319 & 2.03 & 22.4 \\
\hline 4 & 0.002 & 0.141 & 0.05 & 9.86 \\
\hline 5 & 0.009 & 0.010 & 0.65 & 0.70 \\
\hline Mean & 0.020 & 0.185 & 1.40 & 12.97 \\
\hline$\pm \mathrm{SD}$ & \pm 0.01 & \pm 0.1 & \pm 1.3 & \pm 8.1 \\
\hline$P$ & \multicolumn{2}{|c|}{$<0.01$} & \multicolumn{2}{|c|}{$<0.01$} \\
\hline
\end{tabular}




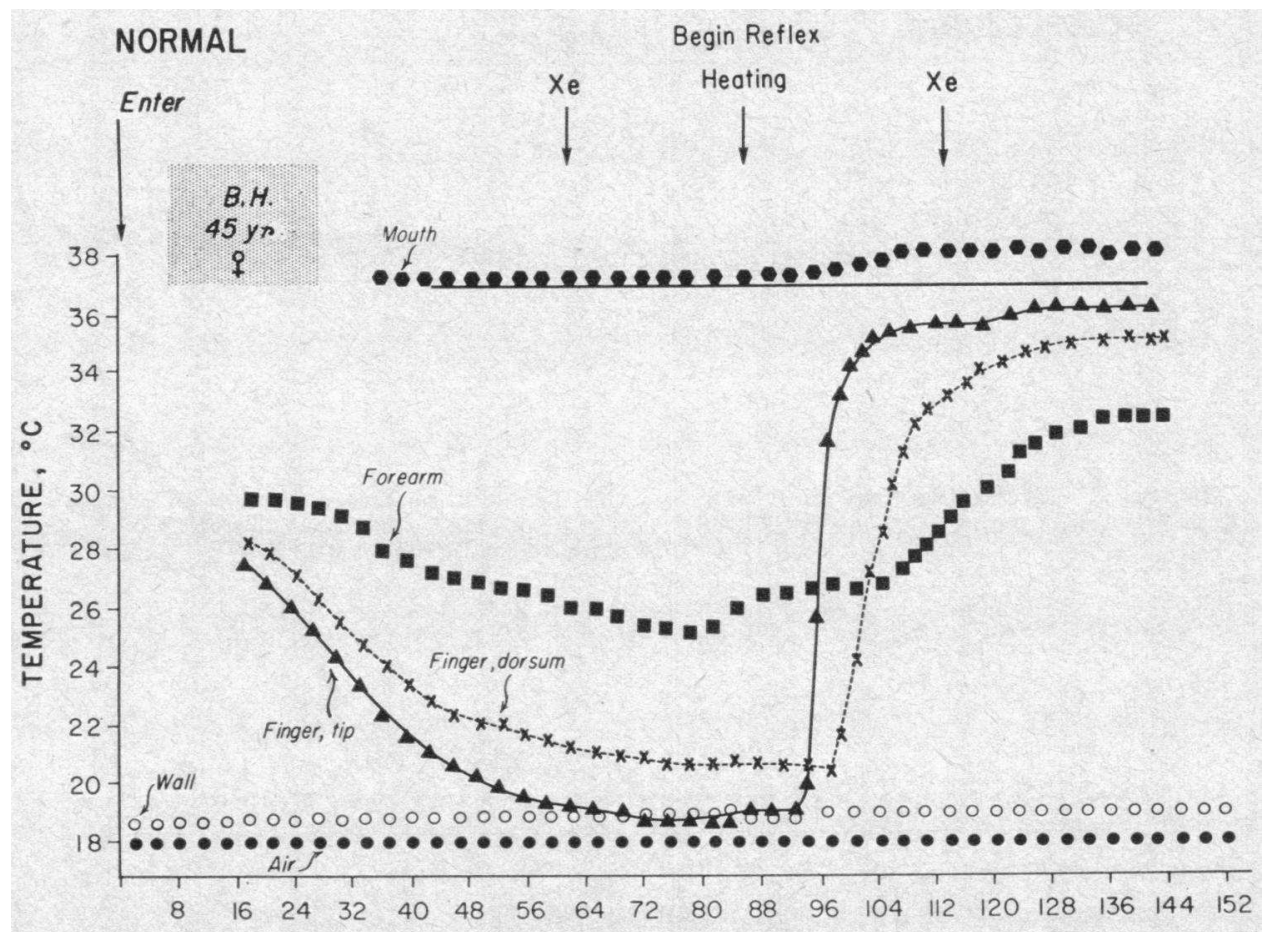

TIME IN MINUTES

FIgURE 3 Temperature recordings during skin blood flow determination in normal subject B. $\mathrm{H}$. The time of entering the cool room, two ${ }^{133} \mathrm{Xe}$ injections and the immersion of one arm in a warm water bath $\left(44^{\circ} \mathrm{C}\right)$ are noted by arrows. The stepwise temperature response of sublingual fingertip, dorsal finger, and forearm sites is demonstrated and is similar to observations described by Lewis (3). The early $(8 \mathrm{~min})$ and rapid rise of finger temperatures after heating was characteristic of the control group. Every fifth actual point is plotted.

to levels similar to the normal subjects occurred while the skin temperatures of scleroderma subjects were distinctly cooler $\left(7.9^{\circ} \mathrm{C}\right)$ than those of the control group (Table II). ${ }^{128} \mathrm{Xe}$ clearance was also determined in the forearm skin of six normal and six scleroderma subjects at room temperature $\left(24^{\circ} \mathrm{C}\right)$. No difference could be detected between the normal ( $K=0.35$ $\pm 0.06, \mathrm{~F}=24.7 \pm 4.1$, mean $\pm \mathrm{SD}$ ) and scleroderma ( $\mathrm{K}$ $=0.34 \pm 0.09, F=24.0 \pm 6.1$ ) subjects studied at this comfortable temperature $(P=>0.8)$. Clearance was not measured in forearm skin in the cool room $\left(18^{\circ} \mathrm{C}\right)$ because forearm skin temperature was not consistently lowered by this cool stimulus; in view of the dissociation between temperature and clearance at more distal sites, such data may be helpful in future studies.

\section{Effect of guanethedine}

The effect of oral pretreatment with guanethedine (30-50 $\mathrm{mg}$ daily in divided doses for 4-6 wk) on clearance and temperature response was studied in five scleroderma subjects (Table III). Clearance after cooling was increased after therapy in all five subjects. The amount of increased clearance varied widely. In three subjects, prolonged clearance returned to within the normal range; in a fourth, very prolonged clearance returned to a near-normal value; in the fifth subject, moderately prolonged clearance improved slightly. Skin temperature responses to reflex warming were essentially abolished in all subjects treated with guanethedine, i.e. skin temperature did not rise after immersion in the water bath, despite appropriate rises in sublingual temperature. After reflex warming, clearance did not increase as it had prior to therapy.

\section{DISCUSSION}

The data of this report represent the first quantitative demonstration of a reduction in capillary skin blood flow in scleroderma during a cooling stimulus. The adaptation of the ${ }^{123} \mathrm{Xe}$ clearance method to measure blood flow in discrete areas of the skin (10) is appropriate to study scleroderma because of the variably expressed and frequently localized cutaneous changes in this disorder. Raynaud's phenomenon, which can occur alone or in association with scleroderma and other connective tis- 


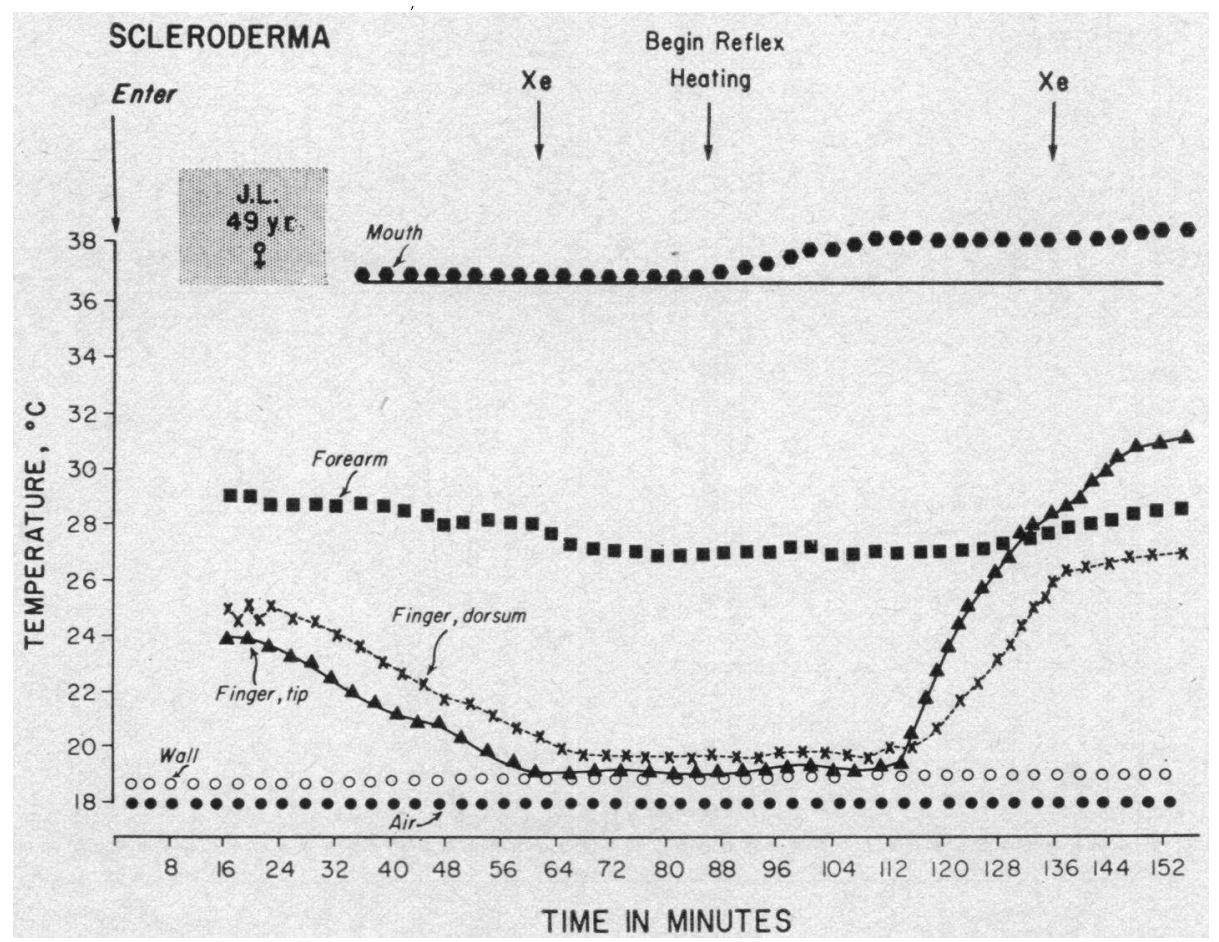

FIgure 4 Temperature recordings during skin blood flow of scleroderma subject J. L. The lower skin temperatures on entering the room, the greater rise in sublingual temperature, and the delayed and flat response in skin temperature to reflex heating were characteristic of scleroderma subjects when compared with normal subjects. Every fifth point is shown.

sue disorders, is a syndrome characterized by marked reduction in the skin circulation in response to cold or other vasoconstrictor stimuli. Consequently, normal and scleroderma patients were studied after $60 \mathrm{~min}$ in an $18^{\circ} \mathrm{C}$ environment; cutaneous responses to systematic alterations in the duration or intensity of the cool stimulus were not studied.

After equilibration at $18^{\circ} \mathrm{C}$, a striking difference in ${ }^{139} \mathrm{Xe}$ clearance from the dorsal finger skin was observed when normal and scleroderma subjects were compared. This difference in cutaneous ${ }^{138} \mathrm{Xe}$ clearance between the groups was not due to altered environmental conditions, since room, oral, and dorsal finger-skin temperatures were similar during the studies. In all normal subjects, ${ }^{138} \mathrm{Xe}$ washout curves were readily resolved into rapid and slow components; in eight of nine studies in scleroderma patients no rapid component was obtained by graphic analysis of washout curves." The ninth scleroderma subject was demonstrated to be hypoxic both before and after the clearance study and may have been resistant to vasoconstriction by cooling because of the strong local vasodilatory effect of hypoxia. Cutaneous blood flow in normal subjects, calculated from the rate

\footnotetext{
${ }^{1}$ Two components of a biexponential washout curve cannot be distinguished by graphic resolution if their half-times differ by less than threefold (13).
}

constant of component I, averaged $16.4 \mathrm{ml} / 100 \mathrm{~g}$ per min and was similar to values reported for normal skin by others (17). Cutaneous blood flow of scleroderma patients, calculated from the single exponential of the washout curve (component II), was significantly reduced at $2.9 \mathrm{ml} / 100 \mathrm{~g}$ per min. Sejrsen has presented direct evidence that component II represents blood flow in the subcutaneous fat. Flow data in scleroderma subjects, obtained from monoexponential curves, must therefore be regarded as maximal values containing a significant proportion of blood flow to the subcutaneous tissue. Any correction for this influence would enhance differences between normal and scleroderma subjects during cooling.

The differences in cutaneous ${ }^{138} \mathrm{Xe}$ clearance need not imply differences in skin blood flow between the two groups if: (a) ${ }^{183} \mathrm{Xe}$ was lost from the injection site by means other than blood flow, (b) countercurrent trappings of the inert gas occurred locally in the scleroderma group, or $(c)$ the blood: skin solubility ratio of ${ }^{183} \mathrm{Xe}$ was different in scleroderma tissue. These three possibilities are unlikely for the following reasons: the observations with occlusion of blood flow by tourniquet confirm previous studies that ${ }^{120} \mathrm{Xe}$ is not lost from skin by diffusion into the air (10); the $18^{\circ} \mathrm{C}$ room temperature made the possibility of ${ }^{138} \mathrm{Xe}$ loss by sweat unlikely. 
A

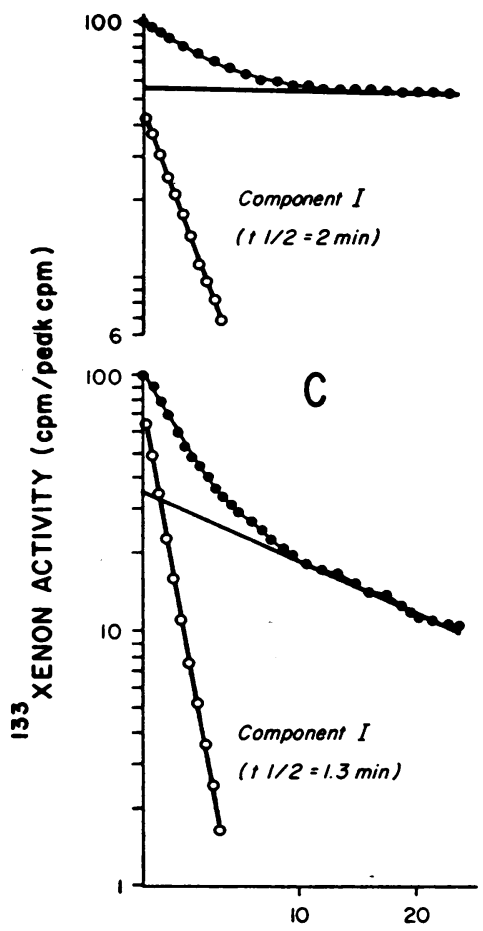

B

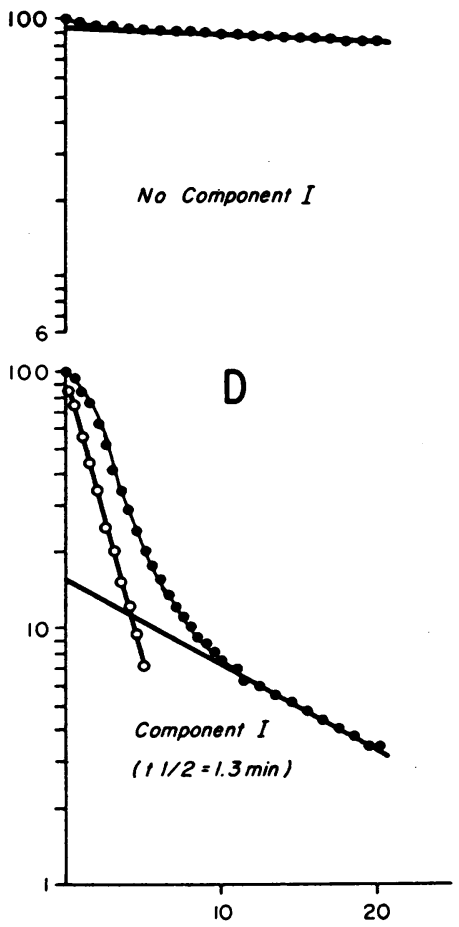

TIME IN MINUTES

Figure $5{ }^{139} \mathrm{Xe}$ disappearance curves in normal subjects ( $\mathrm{A}$ and $\mathrm{C}$ ) and scleroderma subjects ( $B$ and $D$ ) during cooling ( $A$ and $B$ ) and warming $(C$ and $D)$. Every tenth point is shown.

Although a small amount of ${ }^{100} \mathrm{Xe}$ passes into subcutaneous tissue after intradermal injection, Sejrsen has shown that this movement is a function of cutaneous blood flow and does not occur in skin devoid of blood flow (excised or postmortem [10]). Thus diffusion from the skin into deeper tissues is not a detectable cause of ${ }^{120} \mathrm{Xe}$ loss. The possibility of countercurrent trapping (i.e. ${ }^{180} \mathrm{Xe}$ movement into a proximal arm of capillary loops and out of the distal arm of the same loops causing local isotope trapping) in the skin cannot be directly excluded. However, it is unlikely because $(a)$ anatomic studies have found no evidence for arteriovenous anastomoses in the dorsal skin of the proximal finger (18), and $(b)$ the similarity of the ${ }^{12} \mathrm{Xe}$ cutaneous washout curves of normal and scleroderma subjects during warming makes the existence of a vascular countercurrent arrangement in the scleroderma group unlikely. An abnormal affinity of scleroderma skin for ${ }^{128} \mathrm{Xe}$ would appear as a fixed difference in clearance between the two groups under all conditions tested. Since finger skin clearances were not statistically different from normal after reflex warming, and forearm skin clearance was comparable to normal in a warm room, diminished clear- ance in scleroderma subjects at $18^{\circ} \mathrm{C}$ was not likely to be due to abnormal ${ }^{\mathrm{Xe}}$ solubility. The possibility that decreased clearance in scleroderma skin could be explained by indistensible skin, local pressure, and vasospasm cannot be completely excluded in the present study. For two reasons it appears unlikely: (a) Injection volumes did not affect flow below $0.1 \mathrm{ml}$ in normal skin; in scleroderma skin injection volumes were less than $0.05 \mathrm{ml}$ to minimize such effects. $(b)$ Direct vasomotor effects of needle injections have been shown to enhance ${ }^{\mathrm{Xe}}$ clearance in skin, and should not cause decreased clearance in the scleroderma group (10). Therefore, since the experimental conditions do not appear to violate the assumptions of the method, it is concluded that the observed differences in the local clearance rates of ${ }^{100} \mathrm{Xe}$ from the skin reflect significant differences in cutaneous blood flow between normal subjects and patients with scleroderma.

In response to reflex warming, the cutaneous clearance of ${ }^{138} \mathrm{Xe}$ increased markedly in both normal and scleroderma subjects; during this precedure, clearances and calculated blood flows were not significantly different in the two groups. That seven of the nine studies in 
scleroderma patients demonstrated normal cutaneous flow during warming suggests that the extreme reductions in blood flow observed at $18^{\circ} \mathrm{C}$ were, at least in part, functional interruptions of local perfusion. Fixed structural small-vessel disease may have been present in the two patients whose skin blood flow remained subnormal throughout the warming procedure (19). A definite answer to the important question as to whether cutaneous blood flow at room temperature is subnormal in scleroderma patients will require further study of many more patients with the disorder. The slight and not statistically significant differences in clearance after reflex warming, would not explain the distinct and statistically significant differences in temperature responses observed between the normal and scleroderma groups after reflex warming. In separate experiments, flow in affected forearm skin of scleroderma subjects was similar to flow in forearm skin of normal subjects at customary room and skin temperatures. This observation, similar to one reported earlier by others (17), suggests that constant low flow is not a prerequisite for the development of the skin changes in scleroderma.

A second difference between normal subjects and scleroderma patients in the present study was the abnormal response of skin temperature observed in the latter group during reflex warming. In the subjects with scleroderma, the dorsal skin temperatures increased more slowly, and at no time during the warming procedure did they attain the same levels observed in normals studied under identical conditions. This difference in skin temperatures was apparent despite the observations that $(a)$ heat input (assessed from the area under the oral temperature curve) and oral temperatures were the same in both groups, and (b) cutaneous blood flow estimated from ${ }^{139} \mathrm{Xe}$ clearance was also similar in the two groups. These data raise the possibility that the skin of patients with scleroderma has abnormal thermal properties which change the relationship between skin temperature and the skin blood flow observed in normal skin (20). The cool room temperature $\left(18^{\circ} \mathrm{C}\right)$ chosen for the present study and held constant to insure thermocouple accuracy, would accentuate any dissociation between skin temperature and skin blood flow which might exist in scleroderma subjects; these conditions might explain why this observation has not been made in earlier studies (3). There is no direct evidence to support the suggestion that scleroderma skin may have a reduced thermal conductivity. Among the factors which affect skin temperature are blood temperature, blood flow, local heat production, air temperature, the evaporation of moisture, and thermal conductivity. Of these, the thermal properties of the thickened skin of scleroderma subjects would best account for the lowered surface skin temperatures observed. Such a possibility might explain the known inability of such pa- tients to dissipate heat normally, and their enhanced susceptibility to heat stroke (21). However, reduced skin blood flow, the inability to perspire, and a reduction in capillary density in the skin (5) provide alternative explanations for these clinical phenomena (21). The thermal conductivity of scleroderma skin is under study in this laboratory. Also, a separation in responses of the vessels affecting skin temperature (arteriovenous anastomoses) and in the capillary circulation could explain the differences in warming response and clearance in the scleroderma subjects. This hypothesis would suggest a lag in the reflex vasodilatation of arteriovenous shunt vessels when compared with capillaries; such an explanation seems unlikely in view of recent observations that arteriovenous shunt flow is more responsive to reflex sympathetic stimulation than capillary flow (22). A selective assessment of shunt and capillary flow in scleroderma subjects seems warranted (22).

Several indirect and semiquantitative techniques have been used to estimate digital blood flow in scleroderma and Raynaud's syndrome. The original description of vasoconstriction after cooling in Raynaud's syndrome employed techniques of skin temperature measurement and calorimetry (23), which in subjects with normal skin are an accurate reflection of the sum of cutaneous and subcutaneous blood flow (12). Possible differences in subcutaneous tissue and in skin thickness between normal and scleroderma subjects make comparisons which depend on skin temperature and heat exchange difficult to interpret. Relatively rapid blood flow has been observed in the forehead, forearm, and finger skin of scleroderma subjects in a warm room $\left(26^{\circ} \mathrm{C}\right)$ using ${ }^{191} \mathrm{NaI}$ (17). The normal flows observed suggest a response to warming and are perhaps comparable to the flows determined after reflex warming in the present study. No skin temperature data are given. This study is difficult to interpret due to the use of a hydrophilic indicator, the clearance rate of which has been shown to be limited more by capillary pore size than by blood flow, especially when the flow is brisk $(24,25)$.

A heat flow or heat clearance technique was used to study patients with Raynaud's syndrome (many with scleroderma) at $22^{\circ} \mathrm{C}$ and $13.3^{\circ} \mathrm{C}$ (26) ; with this approach all measurements were lower in the patients than in normal subjects. Many investigators have elaborated on the difficulties inherent in using heat flow as a measure of skin blood flow $(12,27,28)$. Again, the sum of cutaneous and subcutaneous effects and the possibility of a variable insulating capacity of thickened skin make it difficult to be certain that blood flow is the only variable measured.

Whether the two abnormalities of scleroderma skin found in the present studies- $(a)$ reduced ${ }^{18} \mathrm{Xe}$ clearance and calculated capillary blood flow at $18^{\circ} \mathrm{C}$ and $(b)$ a subnormal rise in skin temperature during reflex warming 
- contribute to the development of cutaneous atrophy and fibrosis, which define scleroderma, is not known. The local ${ }^{133} \mathrm{Xe}$ clearance technique employed will allow study of the relationship between the microcirculation and the development of fibrosis as the disease progresses. The therapeutic implications of these studies are unclear; the finding that pretreatment with guanethedine prevented the cold-induced reduction of cutaneous blood flow in three of five scleroderma patients warrants further study. Temperature responses in subjects with Raynaud's syndrome following methyldopa therapy are consistent with the present studies using guanethedine, although flow was not directly measured in the earlier study (29).

\section{ACKNOWLEDGMENTS}

The authors would like to thank Dr. David Svahn for help in designing the protocol, Mrs. Helena Plonska and Miss Len Weatherhead for technical assistance, the staff of the Occupational and Physical Therapy Departments for serving as normal controls, and Doctors Charles L. Christian, Stanley E. Bradley, and Robert C. Darling for helpful advice and support.

This investigation was supported by grants from the RGK Foundation, the U. S. Public Health Service (5K03 AM28369-03, HE 10182-04, $5 \mathrm{~K} 3 \mathrm{HE}$ 15031), the Arthritis Foundation (New York Chapter), and the Sidney and Charlotte Lifschultz Foundation.

\section{REFERENCES}

1. Harris, E. D., Jr., and A. Sjoerdsma. 1966. Collagen profile in various clinical conditions. Lancet. 2: 707.

2. Fleischmajer, R., and S. Krol. 1967. Chemical analysis of the dermis in scleroderma. Proc. Soc. Exp. Biol. Med. 126: 252.

3. Lewis, T. 1929-31. Experiments relating to the peripheral mechanism involved in spasmodic arrest of the circulation in the fingers, a variety of Raynaud's disease. Heart. 15 : 7.

4. Brown, G. E., and P. A. O'Leary, 1925. Skin capillaries in scleroderma. Arch. Intern. Med. 36: 73.

5. Redisch, W., J. R. Kulka, and C. McEwen. 1965. Capillaroscopy and three dimensional histologic study of quick-frozen skin biopsies in systemic rheumatic diseases. 11th International Congress of Rheumatology. Buenos Aires, Argentina. (Abstr.)

6. Buchanan, I. S., and D. J. Humpston. 1968. Nail-fold capillaries in connective-tissue disorders. Lancet. 1: 845.

7. Norton, W. L., E. R. Hurd, D. C. Lewis, and M. Ziff. 1968. Evidence of microvascular injury in scleroderma and systemic lupus erythematosus: quantitative study of the microvascular bed. J. Lab. Clin. Med. 71: 919.

8. Heptinstall, R. H. 1966. Pathology of the kidney. Little, Brown and Co., Boston, Mass. 1st edition. 554.

9. D'Angelo, W. A., J. F. Fries, A. T. Masi, and L. E. Shulman. 1969. Pathologic observations in systemic sclerosis (scleroderma): a study of fifty-eight autopsy cases and fifty-eight matched controls. Amer. J. Med. 46: 428 .
10. Sejrsen, P. 1964. Cutaneous blood flow in man studied by freely diffusible radioactive indicators. In Radioaktive Isotope in Klinik und Forschung. $\mathrm{K}$. Fellinger and $\mathrm{R}$. Hofer, editors. Urban and Schwarzenberg, Munich, Germany. 153.

11. Sejrsen, P. 1968. Epidermal diffusion barrier to ${ }^{183} \mathrm{Xe}$ in man and studies of clearance of ${ }^{123} \mathrm{Xe}$ by sweat. $J$. Appl. Physiol. 24: 211.

12. Sejrsen, P. 1969. Blood flow in cutaneous tissue in man studied by washout of radioactive xenon. Circ. Res. 25: 215.

13. Riggs, D. S. 1963. The mathematical approach to physiological problems: a critical primer. Williams \& Wilkins Co., Baltimore, Md. 148.

14. Conn, H. L., Jr. 1961. Equilibrium distribution of radioxenon in tissue: xenon-hemoglobin association curve. J. Appl. Physiol. 16: 1065.

15. Yeh, S., and R. E. Peterson. 1965. Solubility of krypton and xenon in blood, protein solutions, and tissue homogenates. J. Appl. Physiol. 20: 1041.

16. Warner, G. F., E. L. Dobson, N. Pace, M. E. Johnston, and C. R. Finney. 1953. Studies of human peripheral blood flow: the effect of injection volume on the intramuscular radiosodium clearance rate. Circulation. 8: 732.

17. Coffman, J. D., and A. S. Cohen. 1968. Skin blood flow in scleroderma. J. Clin. Invest. $47: 22 \mathrm{a}$.

18. Grant, R. T., and E. F. Bland. 1929-31. Observations on arteriovenous anastomoses in human skin and in the bird's foot with special reference to the reaction to cold. Heart. 15: 385.

19. Mendlowitz, M., and N. Naftchi. 1959. The digital circulation in Raynaud's disease. Amer. J. Cardiol. 4: 580.

20. Edholm, O. G., and A. L. Bacharach. 1965. The Physiology of Human Survival. Academic Press, Inc., New York. 24.

21. Buchwald, I., and P. J. Davis. 1967. Scleroderma with fatal heat stroke. J. Amer. Med. Ass. 201: 270.

22. Coffman, J. D. 1970. Arteriovenous shunt and capillary blood flow in the finger. J. Clin. Invest. 49:19a. (Abstr.)

23. Lewis, T., and G. W. Pickering. 1934. Observations upon maladies in which the blood supply to digits ceases intermittently or permanently, and upon bilateral gangrene of digits; observations relevant to so-called "Raynaud's disease." Clin. Sci. $1: 327$.

24. Braithwaite, F., F. T. Farmer, and F. I. Herbert. 1951. Observations on the vascular channels of tubed pedicles using radioactive sodium. III. Brit. J. Plast. Surg. 4: 38.

25. Lassen, N. A. 1964. Muscle blood flow in normal man and in patients with intermittent claudication evaluated by simultaneous $\mathrm{Xe}^{138}$ and $\mathrm{Na}^{24}$ clearances. J. Clin. Invest. 43: 1805 .

26. Willerson, J. T., R. H. Thompson, P. Hookman, J. Herdt, and J. L. Decker. 1970. Reserpine in Raynaud's disease and phenomenon short-term response to intraarterial injection. Ann. Intern. Med. 72: 17.

27. Hensel, H. 1959. Messkopf zur Durchblutungsregistrierung an Oberflächen. Pfluegers Arch. Gesamte Physiol. Menschen Tiere. 268: 604.

28. Hardy, J. D., and G. F. Soderstrom. 1938. Heat loss from the nude body and peripheral blood flow at temperatures of $22^{\circ} \mathrm{C}$ to $35^{\circ} \mathrm{C}$. J. Nutr. 16: 493 .

29. Varadi, D. P., and A. M. Lawrence. 1969. Suppression of Raynaud's Phenomenon by methyldopa. Arch. Intern. Med. 124: 13 . 